\title{
Zahnmedizin
}

\section{Von reizbar bis fiebrig}

\section{Wie krank macht der Zahndurchbruch?}

Reizbarkeit, vermehrter Speichelfluss, Appetitlosigkeit: Das sind häufige Symptome bei zahnenden Kindern. Fieber und schwere Krankheitszeichen gehören einer neuen Studie zufolge [1] jedoch nicht dazu.

Kinderzahnärzte aus Brasilien haben acht Monate lang den Gesundheitszustand von 47 zahnenden Kleinkindern dokumentiert. Jeden Tag wurde der Zahnstatus untersucht und die Temperatur gemessen. Ebenfalls täglich wurden die Mütter nach dem Vorhandensein von 13 Befunden und Symptomen gefragt.

Die Kinder im Alter zwischen 5 und 15 Monaten, von denen keines an einer chronischen Erkrankung litt, bekamen insgesamt 231 Zähne. Der Zahndurchbruch war verbunden mit einem signifikanten Anstieg der Körpertem- peratur. Im Mittel lagen die Werte allerdings nur $0,12{ }^{\circ} \mathrm{C}$ (aurikulär) bzw. 0,01 ${ }^{\circ} \mathrm{C}$ (axillar) höher als sonst. Die maximal gemessene Temperatur betrug $36,8^{\circ} \mathrm{C}$ bzw. $36,6^{\circ} \mathrm{C}$.

\section{Bei ernsthaften Symptomen} nach anderen Ursachen suchen!

Außerdem trat eine Reihe von Symptomen signifikant häufiger am Tag des Zahndurchbruchs und am Folgetag auf. An erster Stelle waren das: Reizbarkeit, vermehrter Speichelfluss, eine laufende Nase und Appetitlosigkeit. Etwas weniger häufig waren Schlafstörungen, Hautausschlag und Diarrhö. Kein Kind litt an Krämpfen oder Koliken. Nur in seltenen Fällen wurde über Erbrechen berichtet.

Die Studie bestätigt damit, dass es zahlreiche systemische Manifestatio- nen des Zahndurchbruchs gibt. Fieber oder andere schwere Krankheitszeichen gehören nach dieser Studie aber nicht dazu. Das Fazit der Autoren lautet daher: „Wenn Kinder gravierende Befunde und Beschwerden haben, dann sollte man nicht vorschnell das Zahnen dafür verantwortlich machen, sondern zuerst nach anderen Ursachen suchen."

\section{Literatur}

1. Ramos-Jorge J1, Pordeus IA, Ramos-Jorge ML, Paiva SM (2011) Prospective longitudinal study of signs and symptoms associated with primary tooth eruption. Pediatr 128(3):471-476. doi: 10.1542/peds.2010-2697

Paediatr. Paedolog. Austria 2017 · 52:43 DOI 10.1007/s00608-017-0448-2

Online publiziert: 3. Februar 2017

(c) Springer-Verlag Wien 2017

Hier steht eine Anzeige. 